\title{
Light fastness of printing inks: A review
}

\begin{abstract}
Light fastness, in its broadest sense, is the resistance of colours to fading under the influence of a light source. Light fastness is one of the most important physical, and therefore visual, properties sought in both pigments and in the inks. Artificial and natural light causes most pigments to fade resulting in colour change. The light fastness of inks is important especially in the packaging and advertising industries. The posters and advertisements hung on the billboards used especially in outdoor advertising, printed product packaging and other printed products exposed to sunlight require high degree of light fastness. In this study, light fastness and factors affecting the resistance of the colour to the light were investigated and suggestions were made regarding high light fastness in terms of printability.
\end{abstract}

\section{KEY WORDS}

light fastness, blue wool scale, printing ink, colour change, printability

\author{
Cem Aydemir (10, \\ Semiha Yenidoğan \\ Marmara University, \\ School of Applied Science, \\ Department of Printing \\ Technologies, Istanbul, Turkey \\ Corresponding author: \\ Cem Aydemir \\ e-mail: \\ cemaydemir@marmara.edu.tr
}

First recieved: 26.01.2018 Accepted: 05.04.2018.

\section{Introduction}

Light fastness refers to the resistance of a colour to fading under the sunlight (Zeller-Gmelin Corporation, 2017). The colour fastness of the pigments used is essential for the light fastness and weather resistance of printing inks.

Starting from the definition of light fastness; a light source is required for the fading phenomenon to take place. As it is known, the most effective light source is the sun. There must be an object illuminated by the sunlight and an eye observing this object. These three concepts must co-exist in order for the colour sense to emerge. When the electromagnetic waves coming from the light source are at about 380 and 760 nanometer limits, the sense of colour is perceived. These special electromagnetic waves are called light waves. The short wavelengths in the spectrum forms the sense of violet, and as the wavelength increases, the colours of blue, green, yellow, orange and red change in turn (Figure 1).

The sunlight, defined as a broad band of energy emitted from the sun as waves, forms a part of the electromagnetic spectrum. The visible part of the electromagnetic spectrum under the sunlight is between 380 and $760 \mathrm{~nm}$ and is measured in nanometers (Zeller-Gmelin Corporation, 2017).

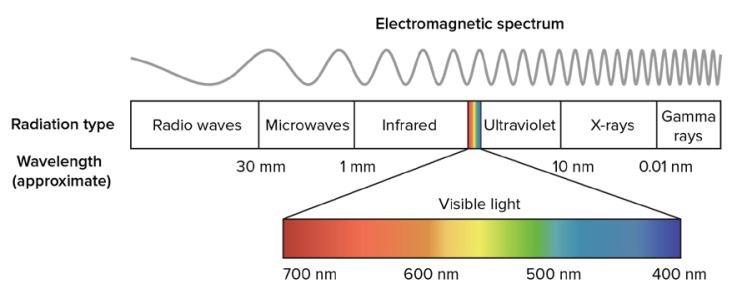

» Figure 1: Electromagnetic spectrum (Khan Academy, 2017).

Fading of an ink is caused by the light, in other words, by the motion of the energy it carries. The energy is inversely proportional to the wavelength. Concentrated energy packets or energy particles from light sources are called photons. Planck has shown that the energy of a light photon can be calculated with the Planck's equation, named after Him (Equation (1)) (Pv Education, 2017). 


\section{Planck's Equation}

$E=h \cdot v$

where,

$h$ : Planck's constant, $h=6,62 \cdot 10^{-34} \mathrm{j} \cdot \mathrm{s}$

$v$ : The frequency of the light, $v=c / \lambda$

where,

c: The speed of the light

$\lambda$ : The wavelength of the light.

If the frequency is replaced by its value, the photon energy;

E: The energy of a photon (Joule) is expressed as follows:

$E=h \cdot v=h \cdot c / \lambda$

This equation implies that the energy $(E)$ of a particle, called photon, is proportional to the frequency (v) and a constant factor $(h)$. This means that low frequency photons such as radio waves have lower energy than high frequency photons such as $\mathrm{x}$-rays.

If this energy is absorbed to some degree (depending on the wavelength) and strong enough, it can break up the colour molecule. The red and yellow organic pigments are much more sensitive compared to the green and blue pigments because they don't have more stable chemical bonds and they also absorb higher energy light. Resistance to light is not only a characteristic of the colourant, but it can also depend on the light source (Ink Technology, 2017).

In outdoor light, solar rays reach earth in three wavelength spectra: $44 \%$ visible (380 to $700 \mathrm{~nm}$ ), $7 \%$ ultraviolet ( 380 to $10 \mathrm{~nm}$ ), and $49 \%$ infrared (above $700 \mathrm{~nm}$ ). Below $380 \mathrm{~nm}$, in the ultraviolet spectrum, degradation by chemical oxidation is accelerated due to the higher frequency, shorter wavelength, and higher energy radiation. This means that, there is enough energy to irreversibly break the chemical bonds of polymers and pigments (Graphix Essentials, 2015).

\section{Chemical Structure of Pigments}

The material that gives the colour to an object is pigment. The perception of each pigment in different colours is entirely due to the chemical structure of that pigment and the bonds making it up. There are two basic types of bond in chemistry. The first of these is ionic bonds and their bond energy is very high. The ionic bond results from the electrostatic attraction of the two elements charged with positive $(+)$ and negative (-) ions to each other. The second one is the covalent bond. This bond forms three different types of bonds according to the number of electrons between two atoms (Western Oregon University, 2017).
C $-\mathrm{C} 1 \sigma$ bond

(1) $\quad \mathrm{C}=\mathrm{C} \quad 1 \sigma$ bond

$1 \pi$ bond

$\mathrm{C} \equiv \mathrm{C} \quad 1 \sigma$ bond

$2 \pi$ bonds

The most common bond type in pigments is the covalent bond. The energies of the single, double, and triple bonds decrease in the same order. In other words, the bond energy of $\sigma$ (sigma) bond is higher than the bond energy of $\pi$ (pi) bond and is expressed as follows (Equation (2)).<smiles>[Y][R]1CO1</smiles>

$E_{\sigma} \gg E_{\pi}$

\section{Degradation of Chemical Structure by UV Rays}

Higher energy/short wavelength UV rays, alpha rays, $x$-rays and cosmic rays reach the earth along with visible long wavelengths from the sun. Some of these high energy wavelengths are absorbed by the ozone layer and the rest are reflected. The reflected UV rays, cause the $\pi$ bond, which is lower in energy than the $\sigma$ bond, to break.

UV (Ultraviolet) rays from natural sunlight or artificial sources such as Fluorescent Bulbs are energetic enough to break down certain bonds in a pigmented ink system and thus modify its molecular structure. Molecular bonds are broken and form 'free radicals' which can then form new bonds with oxygen and other pollutants. This change in molecular structure alters the ability of the pigment to absorb light in the visible region of the spectrum and so can cause a loss of colour strength or variation in hue. These changes are cumulative and irreversible (Caligo Inks, 2012).

\section{Light Fastness Standards}

In the light fastness, besides the degradation of the chemical structure which is the result of thermodynamics, it is necessary to talk about the process as a consequence of the kinetics. In other words, when will the reaction happen. A number of standards have been developed to describe this process. The most important of these is British Standards. There are two methods for light fastness in terms of standards. One of them is the one performed under sunlight, that is, in natural condition and the other is the one performed with Xenon testing device. The results are evaluated according to the Blue Wool Scale (BWS), which is also accepted by the British Standards. Xenon lamp light fastness testers are used to ensure the validity and reproducibility 
of the tests made. The power of the Xenon lamp may vary depending on the characteristics of the device being used. The fact that the concepts such as climate, humidity, and effective distance of light in these devices are standard, ensures the reliability of the obtained values. An important consideration to be taken into account when grading the light fastness is that the deviations that will be made under standard conditions will change the light fastness (Hubergroup Turkey, 2016).

\section{Standards and Accreditation}

The light fastness of printed ink films is expressed by the change in their colourimetric appearance compared to standard blue wool samples.

There are many international standards applied to the light fastness test including ISO 105-B01, ISO 105-B02, BS EN 20105-B02, BS EN 4892-2, BS ISO 2837:1996, BS ISO 12040:1997, BS ISO 2836:1999 and BS ISO 2834:1999 (Smithers Pira, 2017; British Standards Institution, 1997).

DIN 16519, AFNOR Q64-022, DIN 16525 and ISO 2835 standards are detailed methods for printing test samples and measuring light fastness (Brancher, 2017).

The standard specification is DIN 16525, "Testing printing inks and prints in Graphic Industries" and basically tests and classifies the light stability of the following two categories;

a.) Prints made on any printing surface with any printing process, independently from any specific condition,

b.) Test prints made with an ink, strictly complying with the specifications defined in DIN 16519

\section{Measuring Light Fastness and Blue Wool Scale}

In standard inks, the packaging labels contain information regarding the light fastness. For newly developed inks and special mixtures, only average light fastness properties can be given. Or, test results for the light fastness of the pigments in these inks are used as a base. If necessary, more precise data can be obtained by performing light fastness tests of the corresponding inks (Hubergroup Turkey, 2016).

The most commonly used method of measuring light fastness of a material is to expose it to artificial light. A xenon-arc lamp with a spectrum similar to sunlight is used as a light source. In this method, the print samples are gradually subjected to the discolouring process simultaneously with the Blue Wool Scale in the tester that has the xenon-arc lamp and are evaluated according to this scale. This method saves time. (Brancher, 2017; Aydemir \& Özakhun, 2014). Blue Wool Scale was originally developed to characterize the light fastness of textile dyes. It was later accepted as a reference point for testing a variety of colour materials such including ink, paint, plastic and textiles (Western Oregon University (WOU), 2017). This colour scale consists of wool fabric strips coloured with 8 blue colourants, increasing regularly from 1 to 8 (Brancher, 2017). This standard grading, which is composed of 8 light fastness steps, is shown in Table 1 together with the Blue Wool Scale (British Standards Institution, 1997; Aydemir \& Özakhun, 2014; Demirel, 2014; Sun Chemical, 2017).

\section{Table 1}

Blue Wool Scale (BWS)

\begin{tabular}{|c|c|c|}
\hline Blue wool scale & A & Comments \\
\hline & 8 & Outstanding \\
\hline & 7 & Excellent \\
\hline & 6 & Very Good \\
\hline & 5 & Good \\
\hline & 4 & Moderate \\
\hline & 3 & Fair \\
\hline & 2 & Poor \\
\hline & 1 & Very Poor \\
\hline
\end{tabular}

\section{Solidity index Wool scale - Durability of the print}

In the evaluation made according to the results of the outdoor and indoor tests performed in the research laboratories, it was observed that the 8-hour discolouring level in the xenon tester corresponded to approximately 1 month under direct sunlight. The results of this correlation are given in Table 2 .

\section{Table 2}

The light fastness outdoor and indoor correlation according to Blue Wool Scale

\begin{tabular}{c|l|l}
\hline BWS & Xenon Arc Lamp & Sunlight \\
\hline 1 & $0,5-2$ Hour & 5 Hour \\
\hline 2 & $2-4$ Hour & 12 Hour \\
\hline 3 & 1 Day & 2 Day \\
\hline 4 & 3 Day & 5 Day \\
\hline 5 & 6 Day & 12 Day \\
\hline 6 & 8 Day & 1 Month \\
\hline 7 & 12 Day & 2 Month \\
\hline 8 & $>30$ Day & $>3$ Month \\
\hline
\end{tabular}




\section{Average Fading Times}

The light fastness values of the printed ink film on the printing material are relative. Because the Blue Wool Scale values that are appropriate for some products may not be suitable for some others. For example, while having a value of 3 or 4 as the light fastness is enough for the newspaper printing, it may be expected to have a value of at least 6-7 for posters and advertisements hung on billboards. What is to be emphasized here is the life-cycle of a print and the value of the corresponding light fastness. In Table 3, 25\%, $50 \%$ and $100 \%$ fading times are indicated relative to the Blue Wool Scale. These values were obtained in England by fading at $45^{\circ}$ south in the summer. When Table 3 is examined, it can be seen that, the fading in the colour takes place in shorter times in the values between 1 and 4 according to the Blue Wool Scale, while it takes place in longer times in 5 or higher values.

\section{Table 3}

Time-dependent fading rates according to Blue Wool Scale

\begin{tabular}{c|l|l|l}
\hline BWS & $\mathbf{2 5 \%}$ fading & $\mathbf{5 0 \% \text { fading }}$ & $\mathbf{1 0 0 \%}$ fading \\
\hline 1 & 3 Day & 1 Week & 2 hafta \\
\hline 2 & 1 Week & 2 Week & 1 Month \\
\hline 3 & 2 Week & 1 Month & 2 Month \\
\hline 4 & 1 Month & 2 Month & 3 Month \\
\hline 5 & 2 Month & 3 Month & 5 Month \\
\hline 6 & 4 Month & 4 Month & 2 Year \\
\hline 7 & $\begin{array}{l}\text { No fading } \\
\text { after 2 years }\end{array}$ & 1 Year & $\begin{array}{l}\text { No fading } \\
\text { after 2 years }\end{array}$ \\
\hline
\end{tabular}

The light fastness test ends with fading of the test sample. The fading boundary of the blue region on the blue scale at that moment represents the index of light fastness of the ink or printing process (Brancher, 2017). What is desired to be learned is whether the tram and bottom prints will meet the desired conditions in practice. Considering the season, you can get an idea of how many days or weeks the sunlight will be effective on the light stability degree (Table 1).

In addition, the variations of the colour values ( $L * a * b *$ CIE colour spectrum) of the faded print samples can also be measured colourimetrically by spectrophotometer (Aydemir \& Özakhun, 2014). Thus, colourimetric data will be very useful in revealing the difference between differently formulated inks and in achieving the correct result.

It is very difficult in practice to establish precise equivalence among the sunlight stabilities by the light fastness measurement of the prints. In fact, as noted above, different factors depending on the light (density of sunlight, moisture, etc.) can change the printed material (Brancher, 2017). In Table 4, an average equivalent indicator is given.

\section{Table 4}

The light fastness degrees of the inks according to Blue Wool Scale (Hubergroup Turkey, 2016; Aydemir, 2014).

\begin{tabular}{l|l|l}
\hline Degree & $\begin{array}{l}\text { In summer } \\
\text { months }\end{array}$ & $\begin{array}{l}\text { In winter } \\
\text { months }\end{array}$ \\
\hline WS 3 & $4-8$ Day & $2-4$ Week \\
\hline WS 4 & $2-3$ Week & $2-3$ Month \\
\hline WS 5 & $3-5$ Week & $4-5$ Month \\
\hline WS 6 & $6-8$ Week & $5-6$ Month \\
\hline WS 7 & $3-4$ Month & $7-9$ Month \\
\hline WS 8 & Over 1,5 years & Over 2 years \\
\hline
\end{tabular}

\section{Factors that influence light fastness}

Moisture: When the print sample is subjected to fading by the sunlight, the solar radiations are absorbed by the print. The amount of absorption varies depending on the colour. The black colour absorbs the most, while the white colour absorbs the least. This absorption also increases the temperature of the print sample. With the effect of heat, the amount of relative humidity in the printing surface is lower than the relative humidity in the air. The effect of the air and the printing surface temperatures and relative humidity composition on the surface moisture can be defined as effective humidity. As the relative humidity increases, the light fastness decreases. Effective humidity rate is evaluated with red azoic painted moisture sensitive cotton fabric on the basis of Blue Wool Scale. The temperature differences exposed during the light fastness test may not be a direct cause of abnormal results. However, the differences in effective humidity are extremely important and can cause up to four degrees of difference (McLaren, 1956).

According to test results made in England; Blue Wool Scale fading value of a print sample with a relative humidity of $100 \%$ was observed to be 3 . For another print sample with a relative humidity of $0 \%$, on the other hand, the fading value was determined to be 6-7. The relative humidity of the sample with a fading value of 5 under normal conditions and in direct sunlight was determined to be $45 \%$ (Table 5).

\section{Table 5}

The light fastness values of CMYK printing colours depending on different relative humidity ratios.

\begin{tabular}{l|c|c}
\hline Colour & $\begin{array}{c}\mathbf{4 5 \%} \text { relative humidity } \\
\text { Light fastness Value }\end{array}$ & $\begin{array}{c}\mathbf{1 0 0 \%} \text { relative humidity } \\
\text { Light fastness Value }\end{array}$ \\
\hline Yellow & $5-6$ & 4 \\
\hline Magenta & 4 & $1-2$ \\
\hline Cyan & 7 & $6-7$ \\
\hline Black & $6-7$ & $6-7$ \\
\hline
\end{tabular}

Climate: Because of the long-term effect of sunlight, the fading of printed colour films takes place faster in 
summer than it does in other seasons. Since the reflection degrees of the sun rays relative to the earth axis are different, different climates are experienced in different countries at the same time. For instance, the light fastness of printed ink films exposed to sunlight in the northern hemisphere will be lower in summer and higher in winter (Pritchard, 2010).

Direction: The direction from which the sun rays come most effectively is the south direction. Because direct sun rays penetrate only into the half of the hemisphere, its effect is small. The light fastness of prints exposed to sunlight will be lower as they get closer to the equator (Pritchard, 2010).

\section{Alkaline and Acid Structure of the Printing Substrate:} No matter how the ink is compatible with the material, the small amount of alkalinity and acidity that might be present in the material's structure will cause dissolution Dissolved acid or alkaline will degrade the structure of the pigment and reduce its resistance to the light (Caligo Inks, 2012).

Pollution in the Atmosphere: In industrial areas, air contains predominantly dirt and dust particles. These dust and dirt particles cause contamination on the print by adhering to the printed surface. Sulfur dioxide present in the air affects the pigments containing chromium. Thus, the resistance of the ink to the light is reduced (Caligo Inks, 2012).

Ink Film Thickness: While inks applied very thinly on the print substrate fade fast, the light fastness of the thickly applied ink films is higher (Bates, et al., 2011).

Pigmentation: As the pigment concentration increases, the light fastness increases as well. It is more accurate to use high pigmented ink instead of intense ink. Light fastness is not dependent on the amount of pigment concentration, but on the pigment volume concentration.

Mixture Pigments: If the ink consists of more than one pigment, each pigment will be expected to fade to certain extent. Different fading tendencies of the pigments may cause the ink to turn into an unexpected colour.

Additives: UV-absorber can be applied on the print in some situations where the light fastness is desired to be very high. Thus, the incoming sun rays are absorbed by the UV absorber before they reach the pigment or binder and the light fastness of the ink film increases.

Indirect Factors: Factors such as reduced brightness of prints exposed to sunlight and bronzing elimination affect the appearance of colour.

\section{Results and Discussion}

Prolonged exposure to sunlight is only one of many causes of colour fading. The light fastness degree is defined as an ink property that can be examined in the laboratory under a set of parameters. However, the results of the colour fading, which occur when the same printed samples are exposed to external conditions, significantly differ from the original light fastness degree, depending on the weather parameters of the exposed sample.

The reasons for the changes in appearance of the prints are mainly due to the degradation of the colouring material used (pigment or colouring agent). However, light affects not only pigments, but also binders, substrate and even overprint varnish (Brancher, 2017).

Ink colours formulated with pigments having high light fastness can be visually perceived differently under different light sources. This is a natural phenomenon known as metamerism. It is not a defect, and can be solved by the use of correct light sources.

Organic pigments chemically change by the effect of light. Due to this physico-chemical change, continuous deterioration of colour properties takes place over a period of time. The opinions regarding the possible time-dependent resistance to light are usually not very clear (Strohe \& Kock, 2000). Only a few inorganic pigments have unlimited light fastness. All organic and limited number of inorganic pigments, sooner or later, more or less, change with the influence of the light. Besides other reasons, chemical structure, concentration, physical condition of the pigment (particle size, distribution and crystal modification) and finally pigment bearing components affect the degree of change (Hubergroup Turkey, 2016).

The light fastness values of the ink pigments decrease with the dilution ratio. Pigments with high colourant concentration have better resistance to light. The light fastness of a pigment is dependent on the binder resin in which it is dispersed. The amount of resin used also has an influence on the light fastness. In general, the more binder it has, the higher the light fastness (Demirel, 2014).

The degree of the resistance to light depends not only on the pigment type, amount and chemical structure of the ink but also on the applied surface and the film thickness of the ink on the surface of print substrate (Caligo Inks, 2012; Demirel, 2014). Ink film thickness is highly decisive in the resistance to the light. With thick films, fading will occur in the upper layers and not in the lower ones (Caligo Inks, 2012). It won't be possible to continuously keep the ink thickness specified in the standard specifications fixed during printing. This thickness will vary depending on the printing surface and process. When the ink film thickness increases, the light fastness will be 
higher because the number of the pigments to be affected by the light in a certain region will increase. The same is true for more concentrated inks. However, half shade areas will have less light fastness than solid shade areas (Hubergroup Turkey, 2016).

In printing, the most important element is to obtain the correct substrate and ink combination. In case of using the paper of different quality, the paper may fade depending on its structure, and even a blue ink having the maximum light fastness printed on its surface may appear to be faded. In this case, the colour of the print will change even if the pigments are not affected and a greenish shadow will appear on the ink colour due to the fading on the paper. This implies the importance of the choice of a light-fast and stable print substrate surface (Hubergroup Turkey, 2016).

Printed ink film can react with solvent and other chemical substances that come into contact with its surface by filtration of chemicals from overprint coatings, laminating adhesives and even packaging materials.

\section{Conclusion}

Pigment selection is one of the most important and critical factors affecting ink light fastness. Ink pigments have different light fastness degrees and are generally quoted in two levels, full tone and half tone. The scale ranges varies from 1 (very poor, easily fading) to 8 (excellent, minimal fading). Selection should be made according to the ink light fastness rating for the product to be printed.

The lower the pigmentation concentration of the ink, the lower the light fastness (Brancher, 2017). There are many different pigmentation options available for ink manufacturers. The pigmentation degrees in the ink, and the light fastness values of the ink must be known in advance and the printing should be planned accordingly.

The light fastness of an ink is determined by the lowest value of the components having different light fastness. For this reason, the inks expected to have higher fading resistances should be composed of the pigments having higher light fastness. If two or more of the printing inks having different light fastness are blended, the one with lower light fastness determines the mixture ink's light fastness. That is, in such mixtures, what determines the light fastness is the ink having the lowest light fastness (Hubergroup Turkey, 2016; Pritchard, 2010). For this reason, there should be no significant difference in the light fastness values of the inks to be mixed.

When ideally cured, the thick ink film is more resistant to light and weather conditions than a thin ink film (Brancher, 2017). Because, in a given area, there are more pigment particles that will resist the destructive effect of the light. Therefore, very thin ink films should be avoided in printing. In print, halftone areas have lower film thicknesses than solid tone areas. Moreover, ink film thickness is obtained lower in serigraph printing compared to other printing systems. This results in faster discolouration (Graphix Essentials, 2015). For this reason, the print's being solid or halftone and the print type determines the light fastness of the ink.

In indoor lighting, pigments with higher light fastness should be considered for printed surfaces that are permanently close proximity to indoor lighting or exposed to sunlight through windows.

High filler or white pigment content in the ink: inks containing pastel shades (opaque white) and metal (aluminum, imitation metallic brass, etc.) have low light fastness (Brancher, 2017; Leach, 1988). These inks tend to lose colour strength faster. In such cases, pigments that are more resistant and more stable against chemical oxidation should be used. Transparent whites are mainly used for the lightening and colour mixing of printing inks. But, this process decreases the light fastness of the ink. The more transparent the ink film is made, the lower the light fastness becomes. Therefore, intensive bleaching processes should be avoided (Hubergroup Turkey, 2016; Branch, 2017). In general, using a 1:1 ratio of transparent white will reduce the light fastness by 1 degree, and the 1:3 ratio by 2 degrees (Pritchard, 2010).

Overprint oil based varnish, dispersion-UV lacquer and foil lamination generally increases the light fastness of the printed ink film (Hubergroup Turkey, 2016; Stroh \& Kock, 2000). When necessary, an overprint varnish, resistant to weather conditions, and blocking agents, capable of filtering the UV rays in the solar spectrum, should be used. The additional requirements regarding the environmental resistance of the ink coatings applied on the ink films and the chemical overprint varnishes must be checked.

Adhesion of the ink/coating is closely related to the resistance of the ink to external factors. In order to reach high levels in the adhesion, it must be made sure whether there is any need for pre-treatment or special ink usage.

In ink light fastness, in addition to colour pigment, print substrates are also effective. For this reason, attention should be paid to the factor of the print substrates in printing processes with light fastness sensitivity (Aydemir, 2014).

Depending on the intended use and location of the ink, the light fastness values may be high or low. Many parameters mentioned above affect the light fastness. For this reason, only the lightfastness values given by the ink manufacturer companies should not be sufficient. In accordance with the end use conditions of the print- 
ed product; solid or halftone, print substrate, ink film thickness, ink adhesion, colouring operations, top varnish, lac and foil lamination applications, light exposure conditions and time of exposure must be considered. The appropriate lightfastness value should be tested in the laboratory. Thus it may be possible to determine the optimum lightfastness value for the purpose.

\section{References}

Aydemir, C. \& Özakhun, C. (2014) Printing Materials Science. Instambul, Marmara University Publisher. Aydemir, C. (2014) The effect of paper roughness on print colour deviation, lightfastness and print gloss. Marmara Journal of Pure and Applied Sciences. 26 (3), 97-107.

Bates, I., Zjakić, I. \& Milković M. (2011) Lightfastness and Weather fastness of Overprint Pattern Obtained on Polymer Substrates. Technical Gazette [Tehnički Vjesnik]. 18 (3), 349-356.

Brancher (2017) Light fastness. Available from: http:// www.brancher.com/-Resistance-a-la-lumiere-. html?lang=en [Accessed 4th November 2017].

British Standards Institution (1997) ISO 12040:1997 Graphic technology -Prints and printing inksAssessment of lightfastness using filtered xenon arc light. London, British Standards Institution.

Caligo Inks (2012) Lightfastness and Printing Inks. Available from: https://www.google.com/ url?sa $=$ t\&rct=j\&q $=\& e s r c=s \&$ source $=$ web\& $c-$ $\mathrm{d}=1$ \&ved=0ahUKEwiG9pak9sPbAhXkPZoKHOSOCbgQFggqMAA\&url=https\%3A\%2F\%2Fwww.handprinted. co.uk\%2F_literature_130001\%2FCaligo_Technical_Notes_on_Lightfastness\&usg=AOvVaw3pWili-5aic401Ap-rr4-C [Accessed 26th March 2018].

Demirel, M. (2014) General information about printing inks. Available from: http://www.matbaateknik.com.tr/matbaa-murekkepleri-hakkinda-genel-bilgiler-2/ [Accessed 28th August 2017].

Graphix Essentials (2015) Lightfastness of Printed Labels, Quick Guide for Printers. Available from: https:// www.google.com/url?sa=t\&rct=j\&q=\&esrc=s\& source=web\&cd=1\&ved=0ahUKEwjind_g9sPbAhUqxaYKHWDtDUQQFggoMAA\&url=http\%3A\%2F\%2Fwww. graphixessentials.com\%2Fgex\%2F_dl. jsp\%3Fdoc\%3D09284310-LF\%2520article\%2520sec\%25201010.pdf\&usg=AOvVaw2sCt1-sVesd7QtlqHAUtYs [Accessed 16 th August 2017].
Hubergroup Turkey (2016) Technical Data Sheet: Light Fastness of Offset Inks. Available from: http://www.hubergroup.com.tr/tr/bilgi/ teknik-bilgiler/ [Accessed 12th August 2017].

Ink Technology (2017) SYMAD Plastic Technology. Available from: https://sites.google.com/ symad.co.uk/home/printing-technology/ ink-technology [Accessed 22th March 2018].

Khan Akademy (2017) Electromagnetic spectrum. Available from: https://tr.khanacademy.org/science/ biology/photosynthesis-in-plants/the-light-dependent-reactions-of-photosynthesis/a/light-and-photosynthetic-pigments [Accessed 20th October 2017].

Leach, R. H. (1988) The Printing Ink Manual. 4th ed. Springer.

McLaren, K. (1956) Version of record online: 2008. The Importance of Temperature and Relative Humidity in Light Fastness Testing. Colouration Technology. 72 (11), 527-537. Available from: doi: https://doi.org/10.1111/j.1478-4408.1956. tb02114.x [Accessed 16 th December 2017].

Pritchard, G. (2010) The Print Guide. Available from: http://the-print-guide.blogspot.com. $\operatorname{tr}$ /2010/05/fade-to-black-ink-permanence. html [Accessed 17 th December 2017].

Pv Education (2017) Energy of Photon. Available from: http://www.pveducation.org/pvcdrom/properties-of-sunlight/energy-of-photon [Accessed 20 th November 2017].

Smithers Pira (2017) Light Fastness Testing. Available from: https://www.smitherspira.com/ services/print-quality-and-durability/light-fastness-testing [Accessed 13 th July 2017].

Strohe, T. \& Kock, H. J. (2000) Light-fastness and weather resistance in packaging printing. Deutschland, BASF Drucksysteme GmbH.

SunChemical (2017) Determination of Lightfastness (According to ISO 12040). Sheet Europa Manual. Available from: http://www.monochrom.gr/UserFiles/ lightfastness.pdf [Accessed 13 th December 2017].

Western Oregon University (2017) Pete E. Poston. Available from: https://www.wou.edu/las/ physci/poston/ch221/pdf/Ch05-w14-part4. pdf [Accessed 16 th November 2017].

Zeller-Gmelin Corporation. (2017) Light Fastness Printing Inks. Richmond, TechInfoLightfastPaper. Available from: http://legacyfineartprinters.com/images/ Blue\%20Wool\%20Explaination-\%20TechInfoLightfastPaper0109.pdf [Accessed 15th june 2017].

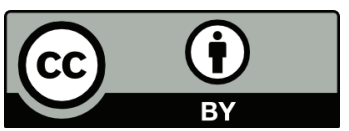

(c) 2018 Authors. Published by the University of Novi Sad, Faculty of Technical Sciences, Department of Graphic Engineering and Design. This article is an open access article distributed under the terms and conditions of the Creative Commons Attribution license 3.0 Serbia (http://creativecommons.org/licenses/by/3.0/rs/). 